\title{
Deskripsi ulang dan sarang Bulbitermes germanus (Haviland) (Isoptera: Termitidae) di Indonesia
}

\author{
Redescription and nest of Bulbitermes germanus (Haviland) \\ (Isoptera: Termitidae) in Indonesia
}

\author{
Syaukani Syaukani \\ Jurusan Biologi, Fakultas Matematika dan Ilmu Pengetahuan Alam, Universitas Syiah Kuala \\ Jalan Syech Abdurrauf No. 3, Darussalam, Banda Aceh 23111
}

(diterima Februari 2017, disetujui Maret 2017)

\begin{abstract}
ABSTRAK
Bulbitermes merupakan salah satu genus endemik dari Wilayah Oriental. Genus ini merupakan genus yang paling kontroversial tentang taksonomi dan informasi biologi sarangnya. Spesimen Bulbitermes germanus (Haviland) dalam penelitian ini dikoleksi dari Indonesia. Warna, pengentingan kepala (constricted head), dan segmentasi antena kasta prajurit merupakan karakter penting yang membedakan rayap ini dengan jenis lainnya. Karakter mandibel dan segmentasi antena kasta pekerja terbukti efektif dalam mereduksi variasi intra-spesifik. Kombinasi antara karakter kasta prajurit dan kasta pekerja menjadi penting dalam mengidentifikasi $B$. germanus. Rayap ini mempunyai sebaran yang luas di Sumatera, Jawa, Borneo, serta Papua. Informasi tentang sarang B. germanus baru pertama dilaporkan dalam artikel ini.
\end{abstract}

Kata kunci: Bulbitermes, Indonesia, rayap, sarang, taksonomi

\begin{abstract}
Bulbitermes is one of the endemic genera distributed in the Oriental Regions. Information on taxonomy and its nesting biology is very limited compared to other genera in the region. Bulbitermes germanus collected from Indonesia was rediscribed. It was found that color, head capsule contriction and, segmentation antenna are important characters for soldier caste, while antennal segmentation and mandibles conditions (worker caste) determined characters for reducing intra-specific variation within genus. Examination of a large number of colonies from various habitats in Indonesia showed that combination both soldier and worker characters were much efective for systematic work for the species. Colony of this species were relatively abundant in the tropical forests of Sumatra, Borneo, Java, and Papua respectively. Nesting strategies of the species was first time reported.
\end{abstract}

Key words: Bulbitermes, Indonesia, nest, taxonomy, termite

\section{PENDAHULUAN}

Rayap merupakan serangga sosial termasuk ke dalam kelompok Ordo Isoptera (Pearce 1997). Populasi suatu koloni mencapai lebih dari satu juta individu (Chhotani 1997). Secara umum, rayap dikenal sebagai hama yang menyerang bangunan yang terdiri atas material kayu, menyerang kayu yang masih hidup dan yang sudah mati, serta sebagai hama dalam pertanian dan perkebunan (Roonwal \& Chhotani 1989). Akan tetapi, rayap merupakan serangga pengurai utama yang sangat penting dalam rantai ekosistem hutan tropis (Collins 1983, 1989; Wood \& Sands 1978; Gathorne-Hardy et al. 2000). Serangga ini memberikan respons yang sangat cepat terhadap

\footnotetext{
*Penulis korespondensi: Syaukani Syaukani. Jurusan Biologi, Fakultas Matematika dan Ilmu pengetahuan Alam, Universitas Syiah Kuala Jalan Syech Abdurrauf No. 3, Darussalam, Banda Aceh 23111, Tel: 082385421973, Faks: 0651-7551381, Email: syaukani@unsyiah.ac.id.
} 
pengrusakan habitat di hutan tropis, terutama pembalakan hutan yang diikuti oleh pembukaan kanopi (Gathorne-Hardy et al. 2001).

Genus Bulbitermes merupakan salah satu genus yang endemik di Wilayah Oriental (Roonwal 1970; Tho 1992; Syaukani \& Thompson 2011). Dari 281 genera rayap yang ditemukan saat ini, Bulbitermes merupakan salah satu genus yang paling kontroversial dalam taksonomi dan sistematikanya. Genus ini sudah lama menjadi perdebatan para peneliti yang menekuni bidang taksonomi rayap (Eggleton 2000; Gathorne-Hardy 2001; Inward et al. 2007; Syaukani \& Thompson 2011). Umumnya, deskripsi taksonomi sampai tingkat spesies dari genus ini tidak jelas dan tumpangtindihnya karakter antara satu dengan lainnya, serta kunci determinasi yang membingungkan (Snyder 1949; Ahmad 1958; Thapa 1981; Tho 1992; Syaukani \& Thompson 2011).

Bulbitermes germanus (Haviland) merupakan salah satu jenis rayap yang banyak tersebar di berbagai tipe hutan di Kawasan Asia Tenggara, terutama di hutan tropis Indonesia. Terbatasnya deskripsi taksonomi dalam beberapa publikasi dan tingginya variasi intra spesies menjadi kendala utama dalam menentukan karakter kunci untuk spesies ini. Keakuratan data taksonomi rayap sangat diperlukan sebagai data dasar dalam kajian tentang biodiversitas dan penerapan teknologi pengendalian bagi spesies yang berperan sebagai hama (Kirton 2005).

Penelitian ini bertujuan untuk mendeskripsi ulang $B$. germanus dan mengungkapkan informasi tentang sarang yang dikoleksi dari berbagai lokasi di Indonesia.

\section{BAHAN DAN METODE}

\section{Lokasi dan waktu penelitian}

Pengoleksian berbagai spesimen rayap $B$. germanus dilakukan sejak 1998-2017 di Indonesia. Spesimen dikoleksi dari berbagai habitat dan ketinggian (1-1.400 m dpl) (Tabel 1).

Pengoleksian rayap dilakukan dengan mengadopsi Standardized Sampling Protocol (Davies 1997; Eggleton et al. 1997; Jones \& Brendell 1998; Jones \& Eggleton 2000), Finding Colony dan Casual Collection (Gathorne-Hardy et al. 2000, 2001; Syaukani et al. 2011, 2016, Syaukani
2012). Setiap mikrohabitat (kayu dan ranting lapuk, serasah, gundukan tanah, di pangkal banir pohon, tumpukan ranting-ranting lapuk diperiksa secara teliti. Bentuk-bentuk sarang rayap yang mengantung, seperti bola pada akar liana atau dahan-dahan pohon, serta sarang-sarang menempel pada batang pohon/banir, serta adanya indikasi lorong-lorong kembara yang menempel pada batang pohon sangat membantu dalam menemukan koloni rayap. Sarang-sarang dari koloni rayap yang ditemukan didokumentasikan, dibuka, dan kemudian rayap dikoleksi. Diusahakan untuk megoleksi sebanyak 50 individu rayap dari berbagai kasta (reproduktif, prajurit, dan pekerja) yang diawetkan dalam $70 \%$ etanol untuk setiap koloni. Pendokumentasian data untuk setiap koloni rayap dilakukan secara manual dan digital.

\section{Identifikasi}

Karakter-karakter morfologi yang akan dipergunakan dalam penelitian ini mengacu kepada Ahmad (1950), Roonwal \& Chhotani (1989), Thapa (1981), Tho (1992), Sands (1998), Gathorne-Hardy (2001), Syaukani (2008, 2010), Syaukani et al. (2011, 2016). Identifikasi dilakukan di Laboratorium Zoologi, Fakultas Matematika dan Ilmu Pengetahuan Alam, Universitas Syiah Kuala (Banda Aceh); Laboratorium Entomologi, Museum Zoologicum Bogoriense (MZB LIPI, Cibinong), Biodiversity Laboratory, Faculty of Science, Kagoshima University (Japan), Biology Department, Faculty of Science, University of Western Ontario (Canada). Konfirmasi taksonomi dilakukan di Termite Research Group, Entomology Department, the Natural History Museum (UK).

\section{Pemotretan spesimen}

Pemotretan spesimen rayap dilakukan di Kagoshima University dan Tokyo Metropolitan University (Japan) dengan menggunakan mikroskop digital (Olympus SZX12 dan Nikon DS-Fi2) dan diedit dengan menggunakan Helicon Focus 6.2.2 (Heliconsoft Ltd).

\section{HASIL}

Dalam penelitian ini berhasil mengoleksi sebanyak 212 koloni rayap yang dikoleksi di Indonesia. Pulau Weh (5 koloni), Pulau Simuelue 
Tabel 1. Lokasi pengoleksian spesimen rayap Bulbitermes germanus dari Indonesia

\begin{tabular}{|c|c|c|}
\hline Lokasi & Provinsi & Kondisi hutan \\
\hline Pulau Weh & Aceh & Tidak terlindungi \\
\hline Pulau Simuelue & Aceh & Terlindungi \\
\hline Taman Nasional Gunung Leuser & Aceh \& Sumatera Utara & Terlindungi \\
\hline Taman Nasional Batang Gadis & Sumatera Utara & Terlindungi \\
\hline Taman Nasional Siberut & Sumatera Barat & Terlindungi \\
\hline Pulau Nias & Sumatera Utara & Tidak terlindungi \\
\hline Pulau Sipora & Sumatera Barat & Tidak terlindungi \\
\hline Taman Nasional Bukit Barisan Selatan & Lampung \& Bengkulu & Terlindungi \\
\hline Kota Bumi & Bengkulu & Tidak terlindungi \\
\hline Pangandaran & Jawa Barat & Terlindungi \\
\hline Taman Nasional Gunung Halimun & Jawa Barat & Terlindungi \\
\hline Kebun Raya Bogor & Jawa Barat & Terlindungi \\
\hline Kebun Raya Cibodas & Jawa Barat & Terlindungi \\
\hline Tangkuban Perahu & Jawa Barat & Terlindungi \\
\hline Gunung Merapi & Jawa Tengah & Terlindungi \\
\hline Taman Nasional Tanjung Puting & Kalimantan Barat & Terlindungi \\
\hline Taman Nasional Betung Kerihun & Kalimantan Barat & Terlindungi \\
\hline Cagar Alam Pararawen & Kalimantan Tengah & Terlindungi \\
\hline Barito Ulu & Kalimantan Tengah & Terlindungi \\
\hline Bukit Suharto & Kalimantan Timur & Terlindungi \\
\hline Malinau & Kalimantan Utara & Terlindungi \\
\hline Pulau Tarakan & Kalimantan Utara & Terlindungi \\
\hline Pulau Bali & Bali & Terlindungi \\
\hline Pulau Lombok & Nusa Tenggara Barat & Terlindungi \\
\hline Pulau Sumbawa & Nusa Tenggara Barat & Tidak terlindungi \\
\hline Sentani & Papua & Terlindungi \\
\hline Gunung Siklop & Papua & Terlindungi \\
\hline
\end{tabular}

(6 koloni), Taman Nasional Gunung Leuser (106 koloni), Taman Nasional Batang Gadis (4 koloni), Taman Nasional Siberut (6 koloni), Pulau Nias (2 koloni), Pulau Sipora (2 koloni), Taman Nasional Bikit Barisan Selatan (7 koloni), Kota Bumi (3 koloni), Pangandaran (2 koloni), Taman Nasional Gunung Halimun (4 koloni), Kebun Raya Bogor (2 koloni), Kebun Raya Cibodas (1 koloni), Tangkuban Perahu (1 koloni), Gunung Merapi (3 koloni), Taman Nasional Tanjung Puting (9 koloni), Taman Nasional Betung Kerihun (16 koloni), Cagar Alam Pararawen (5 koloni), Barito Ulu (12 koloni), Bukit Suharto (Kalimantan Timur) (1 koloni), Malinau (Kalimantan Utara) (4 koloni), Pulau Tarakan (1 koloni), Taman Nasional Gunung Palung (3 koloni), Pulau Bali (1 koloni), Pulau Lombok (2 koloni), Pulau Sumbawa (2 koloni), Sentani (Papua) (1 koloni), dan Gunung Siklop (Papua) (1 koloni).

\section{Deskripsi kasta prajurit}

Kepala (Gambar 1A dan B). Kepala bagian depan berwarna lebih gelap dibandingkan dengan kepala bagian belakang; bagian pangkal nasus terlihat lebih gelap; antena lebih pudar dari warna kepala; kepala berbentuk buah pear dan terdapat pengentingan di bawah pangkal antena, bagian bawah kepala agak rata. Mandibel berupa sedikit apical processes. Panjang kepala 0,91-0,98 mm dan panjang nasus $0,42-0,51 \mathrm{~mm}$ (Tabel 2). Antena terdiri atas 12 segmen (Gambar 1G). Segmen kedua sedikit lebih panjang dari ke empat; ke tiga lebih panjang dari kedua dan ke empat; ke empat lebih pendek dari ke lima; ke enam sampai kedua belas semakin memanjang sampai ke ujung.

Thoraks (Gambar 1F). Pronotum lebih pudar daripada kepala, bagian sekeliling pronotum lebih gelap dibandingkan dengan daerah tengah. Coxae coklat muda; femora kuning; tibiae kuning muda.

Abdomen (Gambar 1A). Tergite berwarna coklat kemerah-merahan. 


\section{Deskripsi kasta pekerja}

Antena (Gambar 1H). kuning keputihan; segmen pertama lebih gelap dari segmen lainnya. 14 segmen: kedua lebih panjang dari ketiga; ketiga yang terpendek dan terpisah tidak sempurna dari segmen ke empat; ke empat lebih panjang dari ke lima; ke enam sampai ke empat belas memanjang ke arah ujung.

Mandibel kiri (Gambar 1D). Gigi bagian atas lebih pendek dari gigi pertama; gigi kedua tidak ada; gigi ketiga terlihat, seperti tertarik ke belakang; gigi ke empat tertutupi oleh molar prominance.

Mandibel kanan (Gambar 1E). Gigi bagian atas dan gigi pertama tidak ada; bagian posterior dari gigi kedua terlihat cembung; lapisan dalam dari molar plate tidak berkembang; notch pada ujung molar plate hanya sedikit berkembang.

\section{Sarang}

Sarang rayap $B$. germanus umumnya terletak tidak tertalu tinggi dari permukaan tanah dengan ukuran yang bervariasi. Pemilihan lokasi penempatan sarang umumnya pada percabangan ranting semak, perdu, serta pohon (Gambar 2). Rayap jenis ini sering membangun sarangnya di sela-sela akar banir Dipterocarpacea di hutan primer Sumatera dan Kalimantan.

Tabel 2. Pengukuran 20 individu kasta prajurit Bulbitermes germanus dari 20 koloni di Indonesia

\begin{tabular}{lc}
\hline Karakter & Range $(\mathrm{mm})$ \\
\hline Panjang kepala termasuk nasus & $1,38-1,42$ \\
Panjang kepala tanpa nasus & $0,91-0,98$ \\
Panjang nasus & $0,42-0,51$ \\
Nasus indeks & $0,53-0,60$ \\
Lebar kepala maksimum & $0,74-0,79$ \\
Tinggi kepala maksimum & $0,58-0,61$ \\
Panjang pronotum & $0,14-0,18$ \\
Lebar pronotum & $0,49-0,55$ \\
\hline
\end{tabular}

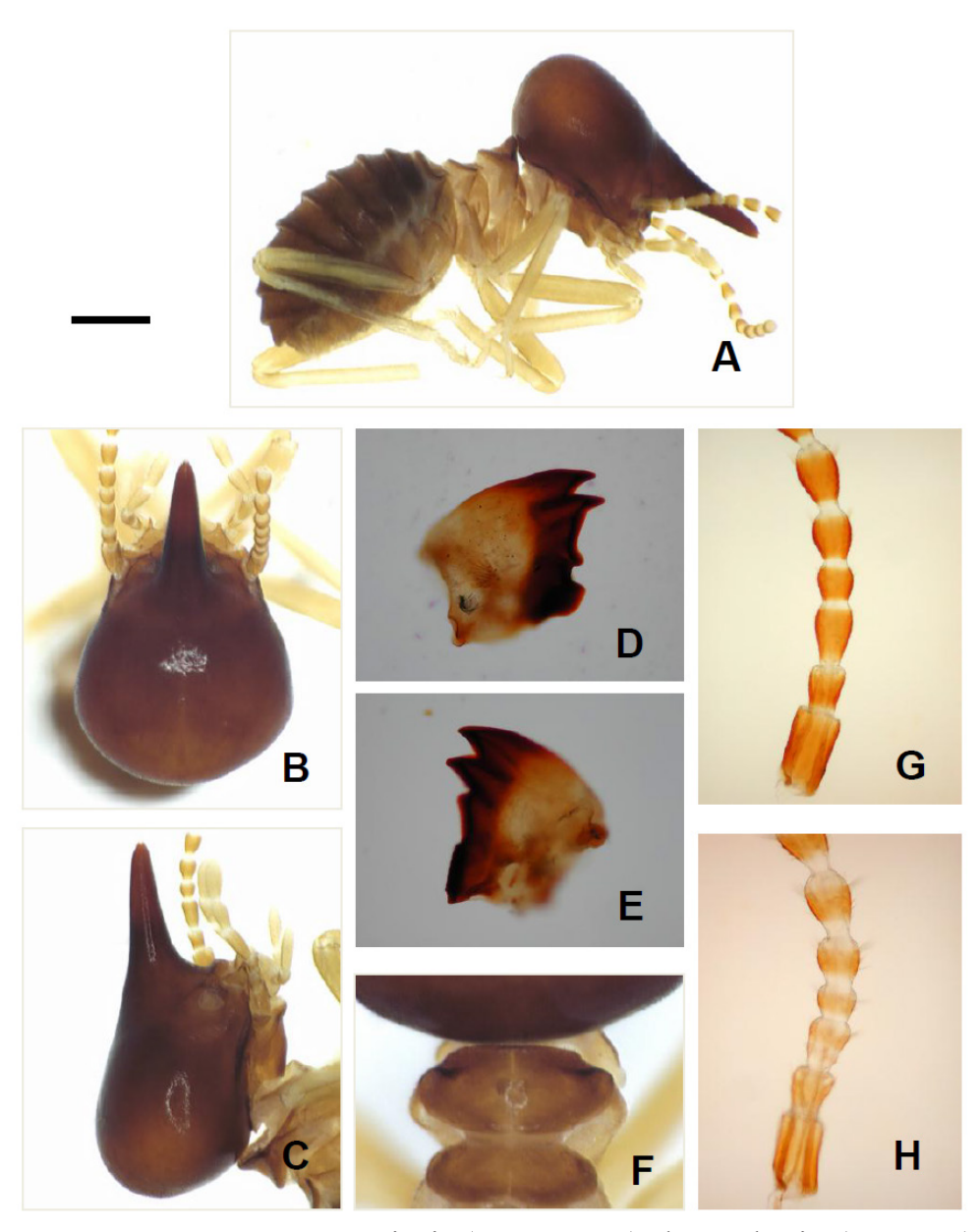

Gambar 1. Bulbitermes germanus. Kasta prajurit (A, B, F, G) dan pekerja (D, E, H). A: pandangan lateral; B: kepala pandangan dorsal; C: kepala pandangan samping; D: mandibel kiri; E: mandibel kanan kanan; F: pronotum; G, H: antena. Skala: 0,6 mm (A), 0,3 mm (B, C), 0,1 mm (D, E, G, $\mathrm{H}), 1,7 \mathrm{~mm}(\mathrm{~F})$. 

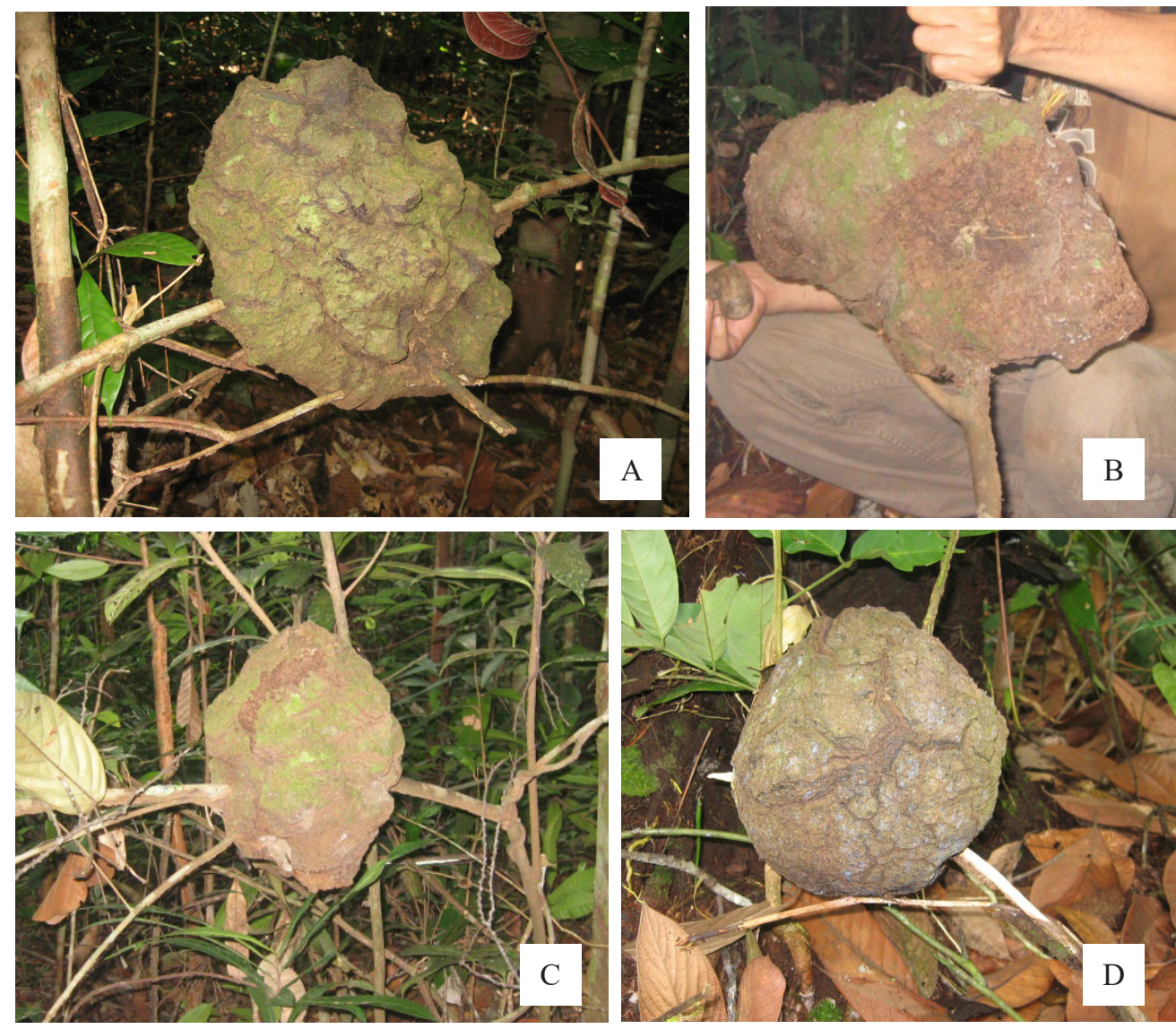

Gambar 2. Morfologi sarang Bulbitermes germanus di Indonesia. A: Taman Nasional Betung Kerihun, Kalimantan; B: Cagar Alam Pararawen, Kalimantan; C: Taman Nasional Gunung Leuser, Sumatera; dan D: Taman Nasional Gunung Halimun, Jawa.

\section{PEMBAHASAN}

Genus Bulbitermes dipisahkan dari Genus Nasutitermes sebagai suatu genus baru untuk mengadopsi adanya sejumlah karakter rayap (Nasutitermitinae) dengan pengentingan di kepala (constricted head) sebagai suatu karakter yang membedakannya dari Genus Nasutitermes (Emerson 1949). Bulbitermes juga dicirikan dengan hanya mempunyai monomorfik kasta prajurit; mempunyai lorong-lorong kembara (non-free ranging type). Kondisi gigi bagian atas (mandibel sebelah kiri) umumnya sama panjang atau lebih pendek dari gigi pertama; notch yang terletak pada bagian ujung dari mandibel sebelah kanan tidak berkembang dengan baik merupakan karakter penting yang mencirikan genus ini berdasarkan karakter kasta pekerja. Beberapa karakter morfologi tersebut di atas telah diuji konsistensinya dengan pemeriksaan karakter molekuler (Syaukani \& Thompson 2011).
Secara morfologi B. germanus sangat mirip dengan B. singaporiensis (Haviland), akan tetapi kondisi segmentasi antena ke empat (kasta pekerja) paling pendek dibandingkan dengan segmentasi lainnya menjadikan karakter kunci untuk membedakan $B$. singaporiensis dengan B. germanus. Aktifnya individu-individu muda dalam berbagai aktivitas di koloni rayap jenis ini sering mengakibatkan bias ketika mengoleksi individu rayap dari sarangnya. Individu yang lebih muda sering berukuran lebih kecil, walaupun terkadang mempunyai warna sangat mirip dengan individu dewasa. Dalam mengoleksi rayap di lapangan, supaya mengoleksi setidaknya kasta prajurit dan kasta pekerja untuk memudahkan dalam mengidentifikasi.

Data pengukuran rayap kasta prajurit dapat membantu dalam mengidentifikasi rayap dari $B$. germanus, akan tetapi jika hanya menggunakan karakter ini saja maka akan sering menimbulkan bias. Pengambungan antara data morfologi dan 
pengukuran untuk kasta prajurit, serta karakter antena dan mandibel dari kasta pekerja merupakan kombinasi yang akurat dalam memisahkan $B$. germanus dari spesies lainnya di Indonesia.

Secara umum, model arsitektur sarang antara $B$. germanus yang terdapat di Kalimantan, Sumatra, dan Jawa tidak menunjukkan perbedaan. Pemilihan mikrohabitat tertentu dalam mendirikan sarang diduga berhubungan dengan strategi rayap untuk mengurangi resiko pemangsaan oleh semut, burung, kadal, beruang, serta orang utan. Beberapa koloni terlihat membangun sarang berbentuk agak bulat atau oval yang bergantung pada liana. Material utama sarang terdiri atas pecahanpecahan kecil kayu lapuk, dedaunan kering/lapuk, dan tanah yang dilekatkan dengan saliva. Lapisan sarang terdiri atas dua bagian, yaitu lapisan luar relatif tipis dan lembut yang lebih berperan dalam mencegah sarang ketika hujan, sedangkan lapisan dalam relatif keras, kaku, serta banyak terdapat material kayu lapuk dan tanah.

Arsitektur sarang terhubung secara rapi antara satu ruangan dengan lainnya dan setiap lorong penghubung selalu dijaga oleh rayap kasta prajurit. Jika diganggu maka rayap kasta prajurit akan segera keluar dari pintu-pintu dan siap menyemburkan cairan kental, sedangkan rayap kasta pekerja bersembunyi di dalam sarang dan baru beraktivitas kembali jika kondisi sudah aman. Berbeda dengan dengan sarang rayap yang berbentuk gundukan di tanah (e.g. Macrotermes), ruangan raja dan ratu (royal chamber) dari $B$. germanus, tidak mudah untuk ditemukan. Diduga karakteristik dari royal chamber pada rayap jenis ini tidak menunjukkan perbedaan yang kontras dengan kondisi ruangan kasta lainnya.

\section{KESIMPULAN}

Penggabungan karakter kasta prajurit dan kasta pekerja merupakan kombinasi yang penting dalam mengidentifikasi rayap $B$. germanus. Warna, morfologi kepala, serta segmentasi antena merupakan karakter kunci dalam membedakan rayap ini dengan jenis lainnya. Rayap $B$. germanus mempunyai variasi intra spesifik yang sangat luas yang mungkin dipengaruhi oleh faktor biogeografi dan ekologi. B. germanus mendirikan sarang dari material campuran kayu, serasah, serta tanah yang lekatkan dengan saliva oleh kasta pekerja. Secara umum, morfologi dan arsitektur sarang rayap jenis ini tidak menunjukkan perbedaan walaupun dikoleksi dari berbagai pulau dan tipe hutan yang berbeda di Indonesia.

\section{UCAPAN TERIMA KASIH}

Peneliti mengucapkan terima kasih kepada Tim Peneliti Rayap dari Leuser Development Project dan LPPM Universitas Syiah Kuala, Konstantina M.B Kameubun (Universitas Cenderawasih), Teguh Pribadi (PGRI Palangkaraya), Kepala dan Staff Taman Nasional dan Cagar Alam di Indonesia, MZB Biologi LIPI, Termite Research Group (NHM, UK), Seiki Yamane (Kagoshima University, Japan), Katsuyuki Eguchi dan Takeshi Yamasaki (Tokyo Metropolitan University, Japan), Graham Thompson (Western University, Canada), Rudolf Scheffrahn (University of Florida, USA) yang membantu dalam konfirmasi taksonomi, foto spesimen, diskusi, dan referensi. Terima kasih kepada Kemeristekdikti yang telah mendanai sebagian penelitian ini melalui Skim Hibah Kompetensi 2017, Kerjasama Luar Negeri dan Publikasi Internasional 2012-2017, PMDSU 2016-2017, serta Skim Fundamental (2012-2013).

\section{DAFTAR PUSTAKA}

Ahmad M. 1950. The phylogeny of termite genera based on imago-worker mandibles. Bulletin American Museum Natural History 95:43-86.

Ahmad M. 1958. Key to Indomalayan termites. Biologia 4:119-198.

Chhotani OB. 1997. Fauna of India-Isoptera (Termites). Vol. II. Calcuta: Director, Zoological Survey of India.

Collins NM. 1983. Termite population and their role in litter removal in Malaysian rain forests. In: Sutton SL et al. (Eds.) Tropical Rain Forest: Ecology and Management. pp. 311-325. Oxford: Blackwell Scientific Publication.

Collins NM. 1989.Termites. In:LiethH.(Ed.) Tropical Rain Forest Ecosystems. Biogeographical and Ecological Studies. pp. 455-471. Amsterdam: Elsevier. doi: https://doi.org/10.1016/B978-0444-42755-7.50032-8.

Davies RG. 1997. Termite species richness in fire-prone and fire-protected dry deciduous dipterocarp forest in Doi Suthep-Pui National 
Park, northern Thailand. Journal Tropical Ecology 13:153-160. doi: https://doi. org/10.1017/S0266467400010348.

Eggleton P, Homathevi R, Jeeva D, Jones DT, Davies RG, Maryati M. 1997. The species richness and composition of termite (Isoptera) in primary and regenerating lowland dipterocarp forest in Sabah, east Malaysia. Ecotropica 3:119-128.

Eggleton P. 2000. Global patterns of termite diversity. In: Abe T (Eds.) Termites: Evolution, Sociality, Symbiosis, Ecology. pp. 25-51. The Netherlands: Kluwer Academic Publishers, Dordrecht. doi: https://doi.org/10.1007/978-94-017-3223-9_2.

Emerson AE. 1949. Descriptions of new genera. In: Snyder TE (Ed.) Catalog of the termites of the world. In: Snyder TE (Ed.) Catalog of The Termites (Isoptera) of The World. Smithsonian Miscellaneous Collections. Vol. 112. pp. 374377. Baltimore: The Smithsonian Institution. Baltimore Press.

Gathorne-Hardy F, Collins NM, Buxon RD, Eggleton P. 2000. A faunistic review of the termites (Insecta: Isoptera) of Sulawesi, including an updated checklist of the species. Malayan Nature Journal 54:347-353.

Gathorne-Hardy F, Syaukani, Eggleton P. 2001. The effects of altitude and rainfall on the composition of the termites (Isoptera) of the Leuser Ecosystem (Sumatra, Indonesia). Journal of Tropical Ecology 17:379-393. doi: https://doi. org/10.1017/S0266467401001262.

Gathorne-Hardy F. 2001. A review of the South-East Asian Nasutitermitinae (Isoptera: Termitidae), with descriptions of one new genus and a new species and including a key to the genera. Journal of Natural History 35:1486-1506. doi: https://doi.org/10.1080/002229301317067647.

Inward DJG, Vogler AP, Eggleton P. 2007. A comprehensive phylogenetic analysis of Termites (Isoptera) illuminates keys aspect of their evolutionary biology. Molecular Phylogenetics and Evolution 44:953-969. doi: https://doi. org/10.1016/j.ympev.2007.05.014.

Jones DT, Brandel MJD. 1998. The termite (Insecta: Isoptera) fauna of Pasoh Forest Reserve, Malaysia. The Raffles Bulletin of Zoology 46:79-91.

Jones DT, Eggleton P. 2000. Sampling termites assemblages in tropical forest: testing a rapid biodiversity assessment protocol. Journal of Applied Ecology 31:191-203. doi: https://doi. org/10.1046/j.1365-2664.2000.00464.x.

Kirton LG. 2005. The importance the accurate termite taxonomy in the broader perspective of termite management. In: Chow-Yang L, Robinson WH (Eds.) Proceedings of the Fifth International
Conference on Urban Pests. pp. 1-7. Singapura: The International Conference on Urban Pests, Printed by Perniagaan Ph'ng @ P\&Y Design Network, Malaysia.

Pearce MJ. 1997. Termites Biology and Pest Management. United Kingdom: CAB International, Willingford.

Roonwal ML. 1970. Termite of the Oriental region. In: Krishna K, Weesner FM (Eds.) Biology of Termites. Vol. 2. pp. 315-391. New York: Academic Press.

Roonwal ML, Chhotani OB. 1989. The Fauna of India and The Adjacent Countries. Calcutta: Zoological Survey of India.

Sands WA. 1998. The Identification of Worker Caste of Termite from Soil of Africa and The Middle East. Wallingford: $\mathrm{CAB}$ International.

Snyder TE. 1949. Catalog of the Termites (Isoptera) of World. Vol. 2. Baltimore: Smithsonian Miscellaneous Collection. Baltimore Press.

Syaukani. 2008. A new species of Lacessititermes (Isoptera, Termitidae, Nasutitermitinae) from the Mentawai islands, Indonesia. Sociobiology 5:459-469.

Syaukani. 2010. Lacessititermes yamanei and Hospitalitermes seikii, two new species of openair processional termites from West Sumatra, Indonesia. Malayan Nature Journal 6:349-358.

Syaukani, Thompson GJ. 2011. Taxonomic notes on Nasutitermes and Bulbitermes (Termitidae, Nasutitermitinae) from Southeast Asia based on morphological and molecular characters. Zookeys 148:135-160. doi: https://doi. org/10.3897/zookeys.148.2055.

Syaukani, Thompson GJ, Yamane Sk. 2011. Hospitalitermes krishnai, a new nasute termite (Nasutitermitinae, Termitidae, Isoptera), from southern Sumatra, Indonesia. Zookeys 148:161169. doi: https://doi.org/10.3897/zookeys.148.1768.

Syaukani. 2012. Checklist of termite (Isoptera) recorded from Bukit Lawang, North Sumatra. Jurnal Natural 12:44-48.

Syaukani, Thompson GJ, Zettel H, Pribadi T. 2016. A new species of open-air processional column termite, Hospitalitermes nigriantennalis sp. $\mathrm{n}$. (Termitidae), from Borneo. Zookeys 554:27-36.

Thapa RS. 1981. Termites of Sabah. Sabah Forest Record 12:1-374. doi: https://doi.org/10.3897/ zookeys.554.6306.

Tho YP. 1992. Termites of Peninsular Malaysia. Malayan Forest Records 36:1-224.

Wood TG, Sands WA. 1978. The role of termites in ecosystems. In: Brian MV (Ed.), Production ecology of ants and termites. pp. 245-295. Cambridge: Cambridge University Press. 